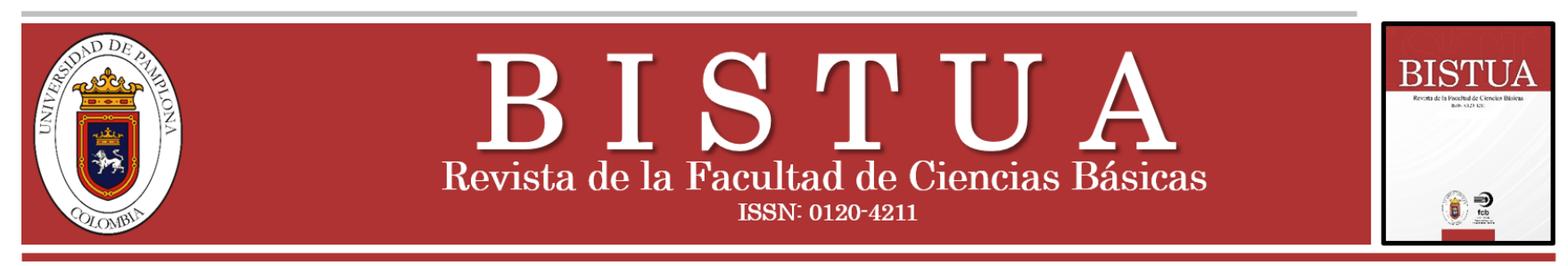

\title{
Inactivación de Escherichia coli productora de toxina Shiga en carne bajo condiciones de refrigeración mediante el aceite esencial de Lippia origanoides
}

\section{Inactivation of Shiga Toxin-producing Escherichia coli in meat under refrigerated conditions using the essential oil of Lippia origanoides}

\author{
Ángela Lizcano ${ }^{\mathrm{a}}$; Raquel Villamizara; Fanny Herrera ${ }^{\mathrm{a}} ;$ Jesús Santos $^{\mathrm{b}}$ \\ ${ }^{a}$ Facultad de Ciencias Básicas, Departamento de Microbiología, Universidad de Pamplona, Colombia. \\ ${ }^{b}$ Departamento de Higiene y Tecnología de los Alimentos, Facultad de Veterinaria, Universidad de León, España. \\ Contacto:fannyh@unipamplona.edu.co
}

Recibido: Marzo 2, 2020. Aceptado: Junio 28, 2020

https://doi.org/10.24054/01204211.v1.n1.2020.4173

\section{Resumen}

Desde el punto de vista de salud pública, el patotipo de Escherichia coli Productor de Toxina Shiga (STEC) es el más relevante en la actualidad, debido a los síntomas y mortalidad que ocasiona, además de su demostrada multirresistencia antibiótica. El principal reservorio de esta bacteria es el ganado vacuno, razón por la cual la ingestión de alimentos derivados de estos animales de abasto es una de las principales fuentes de infección para el ser humano. El objetivo de este estudio fue determinar el efecto antibacteriano de aceites esenciales y extractos de plantas no diluidos frente a cepas STEC in vitro y en muestras de carne. Los resultados del ensayo in vitro revelaron que el aceite esencial de Lippia origanoides fue el que exhibió mayor efecto antimicrobiano evidenciando, en promedio, halos de inhibición en placa de 24,58 mm y una Concentración Mínima Bactericida de $1,8 \%$. Adicionalmente, no se obtuvo crecimiento bacteriano luego de inocular un cocktail de cepas STEC en muestras de carne refrigerada adicionadas con este aceite esencial, durante un periodo de incubación de nueve días. Por tanto, el uso del aceite esencial de Lippia origanoides puede ser un método alternativo de control para este patógeno en carnes. Este es el primer reporte de inhibición de cepas STEC no O157 con Lippia origanoides en muestras de carne.

Palabras clave: Escherichia coli; Toxina Shiga; Aceite esencial; Lippia origanoides; carne.

\section{Introducción}

Escherichia coli productora de Toxina Shiga (STEC) es un patotipo bacteriano cuyo principal factor de virulencia es la producción de toxinas Shiga las cuales son neutralizadas con antitoxinas obtenidas a partir de Shigella dysenteriae, por lo que se les denomina Shiga-Like Toxins o Toxinas Semejante a Shiga (SLT) o Shiga Toxins (Stx); las Stxs se clasifican en dos tipos, Stx1 y Stx2, según la neutralización del efecto citotóxico en células Vero o HeLa con anticuerpos

\section{Abstract}

From a public health point of view, the Shiga Toxin-Producing Escherichia coli (STEC) pathotype, is the most relevant today, due to the symptoms and mortality it causes, in addition to its proven antibiotic multiresistance. The main reservoir of this bacterium is cattle, for this reason the ingestion of food derived from these slaughter animals is one of the main sources of infection for humans. The objective of this study was to determine the antibacterial effect of undiluted essential oils and plant extracts against STEC strains in vitro and in meat samples. The results of the in vitro test revealed that the essential oil from Lippia origanoides was the one that exhibited the greatest antimicrobial effect showing, on average, plaque inhibition halos of $24,58 \mathrm{~mm}$ and a Minimum Bactericidal Concentration of 1,8\%. Additionally, no bacterial growth was obtained after inoculating a cocktail of STEC strains in chilled meat samples added with this essential oil, during an incubation period of nine days. Therefore, the use of the essential oil of Lippia origanoides can be an alternative method of control for this pathogen in meats. This is the first report of nonO157 STEC strains inhibition with Lippia origanoides in meat samples.

Keywords: Escherichia coli; Shiga Toxin; essential oil; Lippia origanoides; meat.

específicos, o por la detección de los genes stx mediante técnicas de biología molecular; las Stx1 y Stx2 también, se conocen como verotoxinas, ya que degradan el cultivo celular de riñón de mono africano (VERO) [1]; estas son producidas en el intestino grueso y ejercen una acción local al inducir apoptosis en las células epiteliales del intestino, dando lugar a diarrea hemorrágica, colitis hemorrágica $(\mathrm{CH})$, necrosis y formación de úlceras. Además, estas toxinas pueden viajar a través del torrente sanguíneo hasta los riñones, dando lugar a inflamación renal. Este daño renal puede evolucionar al 
Síndrome Urémico Hemolítico (SUH), caracterizado por anemia hemolítica, trombocitopenia e insuficiencia renal aguda [2].

La infección por STEC se produce por ingestión de alimentos contaminados, principalmente de origen animal, concretamente carne de origen bovino ya que su principal reservorio es el tracto intestinal de los bovinos. En Estados Unidos, entre el 2009-2015, el patotipo STEC, fue la segunda causa bacteriana de brotes de Enfermedades Transmitidas por los Alimentos, estando entre los agentes que ocasionan mayor porcentaje de hospitalizaciones y muertes [3]. En Latinoamérica, incluida Colombia, se ha demostrado en diferentes estudios el aumento de la prevalencia de esta bacteria en alimentos de origen animal $[4,5,6,7]$.

Como bien es sabido, el tratamiento de las infecciones bacterianas mediante la administración de antibióticos puede ser desfavorable debido al incremento de cepas multirresistentes, concretamente para STEC se ha reportado que, además, pueden favorecer la producción de Stxs [8].

Debido a la creciente preocupación de los consumidores por los efectos secundarios ocasionados por la presencia de conservantes artificiales en los alimentos, la utilización de especias, extractos y aceites esenciales se convierte en una opción de solución a esta problemática. Los aceites esenciales (AE) son una alternativa para el control de bacterias patógenas transmitidas por alimentos. Para el caso de STEC variados estudios han demostrado su efectividad in situ e in vitro $[9,10,11]$.

El objetivo del presente estudio analizó el efecto antibacteriano de diferentes extractos y aceites esenciales de plantas frente a cepas STEC in vitro, empleando el más efectivo in situ en muestras de carne de origen bovino.

\section{Materiales y métodos}

\subsection{Cepas}

Se utilizaron cinco cepas STEC no O157, aisladas a partir muestras de cárnicos crudos que demostraron la presencia de los genes st 1 y stx 2 mediante la prueba de Reacción en Cadena de la Polimerasa [12].

\subsection{Aceites esenciales y extractos:}

Los extractos y AE utilizados fueron provistos por Promitec (Santander, Colombia) obtenidos de la siguiente forma: Extracto de semilla Vitis vinifera (Uva), extracto de Punica granatum (Granada), oleorresina de Capsicum annuum (ají), obtenidos por proceso de extracción con solvente (etanol); Extracto de toronja con adición de ácido cítrico y ascórbico (Citrux), el extracto fue obtenido por el proceso de extracción con etanol de la fruta con cáscara y posterior retiro de este solvente. AE de Citrus reticulata (Mandarina), AE de Citrus aurantifolia (Limón) obtenidos por el proceso de arrastre con vapor de agua sobre la cáscara de la fruta; AE de Eucalyptus globulus (Eucalipto), AE de Cymbopogon martinii (Palmarosa) obtenidos por el proceso de hidrodestilación de hojas de las plantas; $\mathrm{AE}$ de Rosmarinus officinalis (Romero), AE de Lippia origanoides (orégano), AE de Lippia alba (prontoalivio) obtenidos por hidrodestilación de hojas y flores de la planta; AE de Illicum verum (Anis) obtenido por el proceso de hidrodestilación de la semilla de la planta aromática; AE de Eugenia caryophyllata (clavo) obtenido por el proceso de hidrodestilación de los capullos de la flor de la planta.

\subsection{Preparación de cultivos}

Fueron inoculadas cada una de las cepas en Caldo Tripticasa de Soja (TSB) incubando a $37^{\circ} \mathrm{C}$ por $18 \mathrm{~h}$ a $150 \mathrm{rpm}$. A partir de estos cultivos se prepararon los stocks de trabajo, por cepa, ajustando cada uno a una concentración Mcfarland 0,5 (1,5 x $\left.10^{8} \mathrm{UFC} / \mathrm{mL}\right)$.

\subsection{Evaluación de los AE por técnica de difusión en agar:}

Se empleó el método reportado por Cruz et al. (2010) con algunas modificaciones [13]. Se realizó una siembra masiva en agar Tripticasa de Soja (TSA) inoculando, de forma individual, $100 \mu \mathrm{L}$ de cada una de las cepas a una concentración Mcfarland 0,5; Posteriormente se colocaron discos estériles de papel filtro de $6 \mathrm{~mm}$ de diámetro impregnados con $20 \mu \mathrm{L}$ de cada uno de los extractos y AE sin diluir, incluidos los etanólicos. Se incubó a $37^{\circ} \mathrm{C}$ y se realizó seguimiento del crecimiento alrededor de cada disco durante 24 a 48 horas, midiendo los halos de inhibición a través de un calliper. Todos los ensayos fueron llevados a cabo por triplicado. El nivel de susceptibilidad y/o resistencia fue adaptado según los estándares de diámetro de halo establecidos por Ponce et al. (2003) [14]

\subsection{Determinación de la Concentración Mínima Inhibitoria (CMI) y Concentración Mínima Bactericida (CMB) de los $A E$}

La CMI fue determinada por el método de microdilución en pozo, propuesto por Weseler con algunas modificaciones [15]. A cada pozo se le adicionaron $50 \mu \mathrm{L}$ de cada suspensión bacteriana a una concentración McFarland 0,5. Posteriormente, se depositaron $50 \mu \mathrm{L}$ del agente antimicrobiano a diferentes concentraciones, más $100 \mu \mathrm{L}$ de TSB y $10 \mu \mathrm{L}$ de Cloruro Trifenil Tetrazolio, Sigma Aldrich (CTT). Los controles positivos fueron preparados con la suspensión bacteriana, el antimicrobiano y CTT. Para el caso del control negativo se adicionó TSB más CTT. Las placas se incubaron a $37^{\circ} \mathrm{C}$ por $24 \mathrm{~h}$. Todos los ensayos se llevaron a cabo por triplicado. La CMI se determinó como la 
concentración más baja a la cual no se observó viabilidad celular después de 24 h de incubación.

La CMB se determinó empleando la mmetodología propuesta por Horna et al. (2015) con algunas modificaciones [16]. Se extrajeron $100 \mu \mathrm{L}$ de los pozos en los cuales no se observó crecimiento visible de cada bacteria (inhibición de crecimiento). Esta suspensión se inoculó en placas Petri con TSA y se incubó durante 24 horas a $37^{\circ} \mathrm{C}$. La Concentración Mínima Bactericida fue tomada como aquella capaz de inhibir completamente el crecimiento bacteriano o eliminar al 99,9\% de bacterias, comparándolo con el control positivo.

\subsection{Evaluación del efecto antibacteriano del AE de Lippia origanoides in situ}

\subsubsection{Preparación de las cepas}

A partir de cinco cepas de STEC crecidas en TSA, se realizaron tres pases sucesivos cada $24 \mathrm{~h}$ de cada cepa en caldo Brain Heart Infusion (BHI), incubando a $37 \pm 1{ }^{\circ} \mathrm{C}$.

\subsubsection{Preparación de las muestras}

Se siguió la metodología sugerida por Selim et al. (2011) [17] y Djenane et al. (2012) con modificaciones [18]. Piezas de carne de origen bovino de primera calidad, se sumergieron en agua hirviendo durante 5 minutos, con el fin de reducir la cantidad de microorganismos adheridos a la superficie del músculo de la carne; la superficie cocida del músculo fue eliminada con cuchillos estériles en condiciones asépticas. Posteriormente se picaron las piezas anteriores empleando una licuadora estéril; porciones de $25 \pm 0.1 \mathrm{~g}$ se colocaron en bolsas resellables estériles.

\subsubsection{Inoculación de Escherichia coli Toxina Shiga en las muestras de carne}

Se preparó un cocktail con cinco cepas de STEC tomando $0,5 \mathrm{ml}$ de cada una, obtenidas como se mencionó anteriormente; posteriormente se realizaron diluciones del pool hasta obtener $5,0 \times 10^{5} \mathrm{CFU} / \mathrm{g}$ en agua peptonada $0,1 \%$. Seguidamente se tomaron 5 piezas de carne molida, cada una de $25 \mathrm{~g}$ y se sumergieron en el inóculo anterior durante 20 minutos. Posteriormente se aplicó, a través de aspersión manual, el AE de Lippia origanoides $(L O)$ al doble de la CMI obtenida. Homogeneizando manualmente y almacenando a temperatura de refrigeración durante un lapso total de 9 días. Como controles positivos se tomaron 3 porciones de carne inoculadas con el pool de bacterias. Como controles negativos se tomaron 3 porciones de carne aspersadas con el AE de $L O$ sin inoculación bacteriana. Todos los controles fueron mantenidos a las mismas condiciones de refrigeración.

\subsubsection{Seguimiento del efecto antibacteriano}

Para cada tiempo (0, 1, 3, 6 y 9 días), las porciones de 25 $\mathrm{g}$ de carne fueron asépticamente añadidas a $225 \mathrm{ml}$ de agua de peptona estéril al $0,1 \%$, homogenizando, realizando diluciones seriadas (1/10) en agua de peptona estéril al $0,1 \%$ e inoculando $(0,1 \mathrm{ml})$ sobre la superficie del medio de cultivo MacConkey Sorbitol suplementado con Cefixima y Telurito (CT-SMAC), incubando durante $24 \mathrm{~h}$ a $37^{\circ} \mathrm{C}$. Los recuentos obtenidos en cada tiempo se expresaron como el log de $\mathrm{UFC} / \mathrm{g}$ de muestra analizada.

\subsection{Análisis estadístico}

Se aplicó un Análisis de Varianza (ANOVA). Se utilizó un nivel de significancia del $95 \%$ (p-valor $<0,05$ ) para determinar la existencia de diferencias significativas en los ensayos realizados.

\section{Resultados}

\subsection{Evaluación de los AE y extractos por técnica de difusión} en agar

El AE de LO, AE de Eucalyptus globulus y el extracto Citrux fueron los que exhibieron mayor efecto antibacteriano con halos de inhibición superiores a $15 \mathrm{~mm}$ para las diferentes cepas analizadas (Fig. 1 y Tab.1).

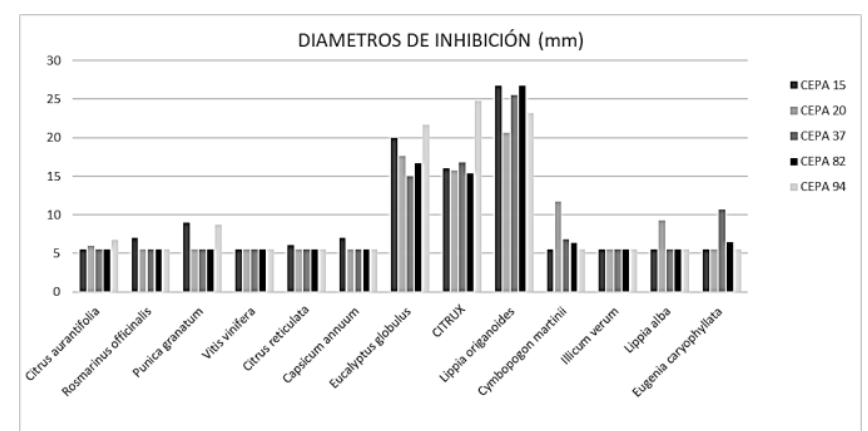

Figura 1. Sensibilidad mostrada por las cepas STEC frente a AE y extractos (promedio en mm de los halos de inhibición).

Tabla 1. Efecto inhibitorio del extracto y AEs más inhibitorios sobre el crecimiento de las diferentes cepas STEC, mediante la técnica de difusión en agar.

\begin{tabular}{|c|c|c|c|c|c|}
\hline & \multicolumn{5}{|c|}{ CEPA } \\
\hline & 15 & 20 & 37 & 82 & 94 \\
\hline $\mathrm{AE}$ & $20,00^{1}$ & 17,65 & 15,02 & 16,68 & 21,7 \\
\hline $\begin{array}{l}\text { Eucalyptus } \\
\text { globulus }\end{array}$ & & & & & \\
\hline $\begin{array}{c}\text { Extracto } \\
\text { Citrux }\end{array}$ & 16,00 & 15,71 & 16,77 & 15,39 & 24,8 \\
\hline $\begin{array}{l}\text { AE Lippia } \\
\text { origanoides }\end{array}$ & 26,78 & 20,64 & 25,52 & 26,77 & 23,2 \\
\hline
\end{tabular}




\subsection{Concentración Mínima Inhibitoria (CMI) y} Concentración Mínima Bactericida (CMB) del AE de L. origanoides

Teniendo en cuenta que el $\mathrm{AE}$ de $L O$ fue el que reveló mayor acción antibacteriana, se procedió a determinar la CMI y CMB para este AE; al iniciar el ensayo con concentraciones del $2,0 \%, 3,0 \%, 4,0 \%, 5,0 \%$ y $6,0 \%$ se logró demostrar inhibición del crecimiento bacteriano por lo que se realizó de nuevo la prueba de microdilución en pozo disminuyendo las concentraciones a valores entre $1,0 \%$ y $2,0 \%(1,2 \%$; $1,4 \% ; 1,6 \% ; 1,8 \%)$, determinando que la CMI y CMB promedio fue de $1,8 \%$.

\subsection{Evaluación del efecto antibacteriano del AE de Lippia origanoides in situ}

Se trabajó con el doble de la CMI obtenida para este AE, es decir 3,6\%. Para cada una de las diferentes pruebas realizadas (control positivo, control negativo, ensayo), sólo se presentó crecimiento de STEC en el medio de cultivo CTSMAC para el caso del control positivo donde las muestras de carne estaban impregnadas únicamente con la bacteria. Para el caso del denominado "ensayo" (muestras de carne inoculadas con el cocktail de STEC + AE LO) y control negativo (muestras de carne $+\mathrm{AE} L O$ ) no se detectó crecimiento bacteriano en ningún tiempo ni réplica (Fig. 2).

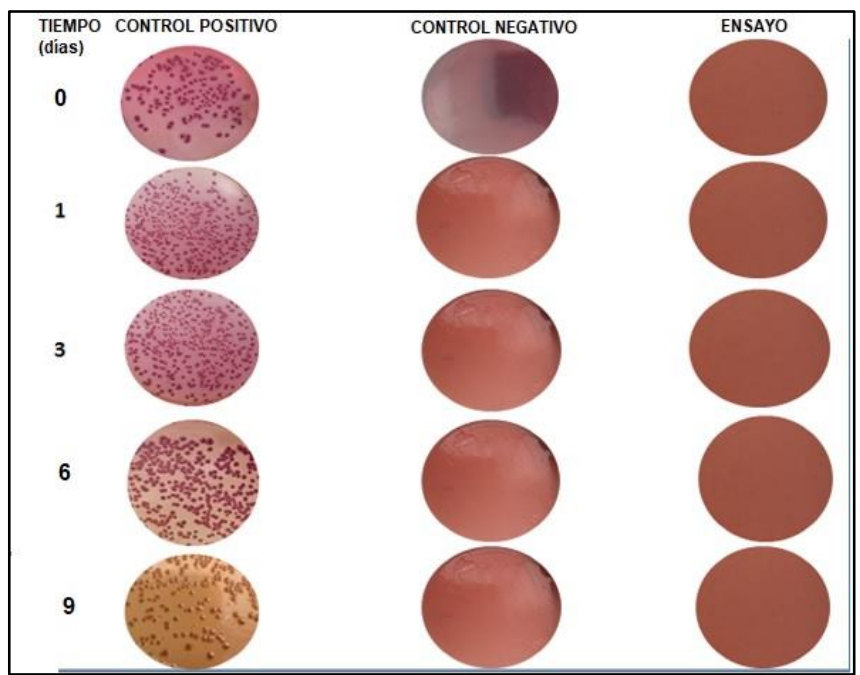

Figura 2. Resultados del efecto inhibitorio de Lippia Origanoides en muestras de carne inoculadas con un cocktail de STEC en agar CT-SMAC. Control positivo: muestras de carne + STEC; control negativo: muestras de carne + AE LO; Ensayo: muestras de carne + STEC + AE LO).

La figura 3 evidencia los resultados obtenidos para cada una de las réplicas con el control positivo, único ensayo el que se obtuvo crecimiento bacteriano, de hecho, los resultados no mostraron una reducción estadísticamente significativa $(\mathrm{P}>0.05)$ en los recuentos microbianos a partir del primer día durante los nueve días de incubación.

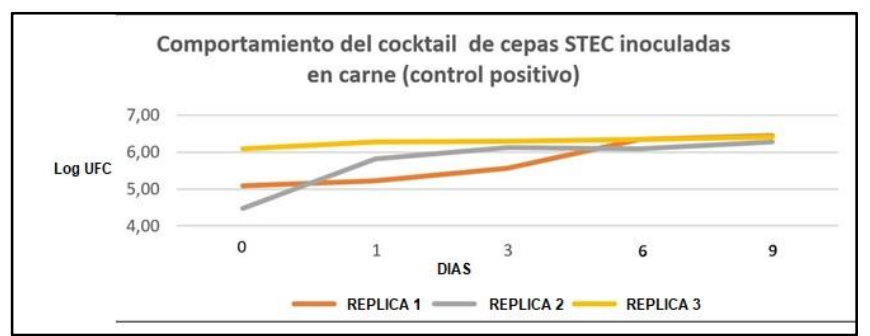

Figura 3. Comportamiento de cepas STEC en el control positivo en las diferentes réplicas durante 9 días.

\section{Discusión de resultados}

El AE de $L O$ fue el que demostró mayor acción antibacteriana (Tab. 1); Stashenko et al. (2010) [19] encontraron al menos tres quimiotipos de esta planta en Colombia, dependiendo de su composición de $\alpha-y \beta$ felandreno, p-cimeno y limoneno (quimiotipo A), carvacrol (quimiotipo B) o timol (quimiotipo C); Olivero-Verbel et al. (2010) [20] cuantificaron los principales componentes del AE de LO de plantas nativas de la zona norte central de Colombia (región de origen de las plantas utilizadas en nuestro estudio), siendo: p-cimeno $(15,7 \%)$, trans- $\beta$ Cariofileno $(9,4 \%), \alpha$-terpineno $(6,9 \%)$, monoterpenos con una comprobada acción antibacteriana incluso frente a Escherichia coli $\mathrm{O} 157: \mathrm{H7}$, uno de los principales serotipos STEC [21]; el mecanismo de acción de estos monoterpenos hidrocarbonados se atribuye a sus propiedades lipofílicas que afectan la integridad de la membrana bacteriana [22].

Adicionalmente, se obtuvo una importante inhibición del crecimiento bacteriano de las cepas STEC en la prueba de difusión en agar con el extracto de Eucalyptus globulus (Tab. 1). Resultados similares obtuvieron Mota et al. (2015) [23], quienes reportaron la inhibición de Escherichia coli con $\mathrm{AE}$ de hojas de Eucalyptus globulus no diluido; por otro lado, Thielmann et al. (2019) [24] evidenciaron reducida actividad antimicrobiana de este AE frente a cepas de E.coli, al igual que Djenane et al. (2011) [25], quienes demostraron mayor sensibilidad de Staphylococcus aureus comparado con E.coli O157:H7. Entre los componentes mayoritarios de las hojas de Eucalyptus globulus nativo de zonas específicas de Colombia se tiene Eucaliptol o 1,8-Cineol (82.27\%), limoneno (3.7\%), $\alpha$-pineno (3.16\%), guaiol $(2.76 \%)$, terpinen-4-ol $(1.4 \%)$ y linalol $(1.3 \%),(1,3 \%), \alpha-\mathrm{T}$ erpineol $(1,2 \%)$, compuestos que desestabilizan la permeabilidad de la membrana celular bacteriana, comprometiendo su integridad [26].

El extracto de Citrux fue el tercer extracto que mejores resultados arrojó en la prueba de difusión en agar (Tab. 1), el cual contenía extracto de toronja; al respecto, autores como Callaway et al. (2008) [27] han reportado la disminución del crecimiento de cultivos de E.coli O157:H7 mediante la adición de productos cítricos al 2,0\%, efecto que se debe a la presencia de AEs presentes en la cáscara de las frutas cítricas 
como son citruleno y limoneno, que pueden ejercer una potente acción antimicrobiana. De forma similar Sanz-Puig et al (2016) [28], demostraron el efecto bactericida de subproductos de cítricos a concentraciones del 5,0\% y 10,0\% reduciendo poblaciones de E. coli $\mathrm{O} 157$ : $\mathrm{H} 7$ hasta de 1.5 $\log _{10}$. Pendleton et al (2012) [29] estudiaron el efecto de aceites prensados de naranja frente a cepas de E. coli O157:H7 aisladas de carne, demostrando la inhibición de crecimiento bacteriano a partir de una concentración del $0,2 \%$ a $37^{\circ} \mathrm{C}$.

Los valores de inhibición obtenidos en las pruebas de difusión en agar y CMI en nuestro estudio pueden ser dispares con los obtenidos por otros autores, lo que es posible debido a la variada composición de los agentes antimicrobianos activos de los AE. Esta composición depende de diferentes factores, incluyendo área geográfica donde se cultivó la planta, prácticas culturales, temporada de cosecha, método de extracción, y método de detección de actividad antibacteriana [24].

Debido al abuso en la aplicación de antibióticos en la producción animal, el consumo de sus alimentos derivados representa un mayor riesgo de infección para el ser humano con microorganismos resistentes a antibióticos; por esta razón el presente estudio analizó el efecto del AE de $L O$ sobre un cocktail de cepas STEC inoculadas en muestras de carne, logrando evidenciar la reducción del crecimiento bacteriano a niveles indetectables. La concentración de la AE necesaria para ejercer actividad antimicrobiana es importante cuando la intención es usarlos en alimentos. Uno de los requisitos para una reducción ideal de patógenos es la capacidad de lograr una reducción de $5 \mathrm{log}$ en la viabilidad [9], requisito que fue conseguido en este estudio ya que luego de inocular las muestras de carne con una concentración inicial aproximada de $5,0 \times 10^{5} \mathrm{CFU} / \mathrm{g}$ y $3,6 \%$ del AE de $L O$, no fue posible detectar crecimiento en ningún tiempo de incubación.

Varios estudios han evidenciado la actividad antibacteriana de diferentes AE sobre E. coli $\mathrm{O} 157: \mathrm{H} 7$ en muestras de carne; por ejemplo, Selim (2011) [17], obtuvo una reducción de $2 \log$ en E. coli O157:H7 en muestras de carne adicionadas del AE de tomillo al 1,0\%. De forma similar, el AE de Carum copticum $0,75 \%$ adicionado en carne molida, redujo la población de E. coli $\mathrm{O} 157: \mathrm{H} 7$ en $2.12 \log _{10}$ después de 9 días a $4^{\circ} \mathrm{C}$ [30]. AE de cítricos extraídos de cáscara de naranja redujeron la concentración de cepas análogas de E. coli $\mathrm{O} 157: \mathrm{H} 7$ en filetes de carne [31]. A pesar de esto son limitados los estudios del efecto de $\mathrm{AE}$ sobre cepas STEC no 0157 en alimentos, concretamente, Hatab et al (2016) [9], evaluaron la supervivencia de siete cepas de STEC no 0157 inoculadas en una mezcla de líquido prensado (conteniendo col rizada, espinacas, pepino, apio, manzana verde, jengibre y limón) adicionado de diferentes $\mathrm{AE}$, revelando la reducción de las cepas a un nivel indetectable a $4{ }^{\circ} \mathrm{C}$, mediante la adición de $\mathrm{AE}$ de tomillo y romero a la mezcla prensada en frío. De acuerdo con la bibliografía consultada, nuestro estudio es el primer reporte de control de STEC no O157 con AE de $L O$ en muestras de carne.

Es bien sabido que se necesita mayor concentración de EO en alimentos que in vitro para lograr el mismo efecto antibacteriano; las grasas, proteínas, contenido de agua, antioxidantes, conservantes, $\mathrm{pH}$, sal y otros aditivos son relevantes en la sensibilidad bacteriana a bioconservantes. Adionalmente, la tasa de difusión de los principios activos del petróleo y sus bajas presiones de vapor también pueden limitar los microorganismos exposición [32]; por estas razones, se utilizó el doble de la CMI del AE de $L O$ para los ensayos in situ, resultando suficiente para inhibir el crecimiento de las cepas STEC en las muestras de carne a temperaturas de refrigeración.

A pesar de su actividad bactericida, hay varias cuestiones relativas a aplicación del aceite de $L O$ en la industria alimentaria. Su volatilidad y poca solubilidad en agua, dificulta su aplicación directa en los alimentos. Además, los atributos de aroma son uno de los factores que limitan la aceptación sensorial de los productos alimenticios conservados con $\mathrm{AE}$, por lo que es necesario analizar los efectos sinérgicos de otros agentes como son adición de ácidos orgánicos, utilización de atmósferas modificadas, entre otros, y de esta manera minimizar las concentraciones requeridas para lograr un particular efecto antibacteriano sin afectar negativamente la aceptabilidad sensorial del alimento, aspecto que será objeto de estudio por los autores.

\section{Conclusiones}

Dentro del grupo de extractos y aceites esenciales ensayados, El AE de L. origanoides (LO), AE de Eucalyptus globulus y el extracto Citrux fueron los que exhibieron mayor efecto antibacteriano en el ensayo de difusión en placa siendo en promedio $24,6 \mathrm{~mm}, 18,21 \mathrm{~mm}$ y $17,7 \mathrm{~mm}$, respectivamente; el AE de Lippia origanoides a una concentración de 3,6\% demostró efecto bactericida sobre las cepas de STEC inoculadas en muestras de carne refrigerada.

\section{Reconocimientos}

A la empresa Promotora de Soluciones Biotecnológica PROMITEC S.A.S. por aportar los aceites esenciales y extractos utilizados en este estudio.

\section{Referencias}

[1] Bryan A, Youngster I, McAdam A. Shiga Toxin Producing Escherichia coli. Clin Lab Med. 35(2) (2015) 247-72

[2] Gyles, C. Shiga toxin-producing Escherichia coli: an overview. J. Anim. Sci 85 (2007) E45-E62. 
[3] Dewey-Mattia D, Manikonda K, Hall A, Wise M, Crowe S. Surveillance for Foodborne Disease Outbreaks - United States, 2009-2015. MMWR Surveill Summ. 67(10) (2018) 1-11. doi: 10.15585/mmwr.ss6710a1.

[4] Rúgeles 1, Bai J, Martínez A, Vanegas M, Gómez-Duarte O. Molecular characterization of diarrheagenic Escherichia coli strains from stools samples and food products in Colombia. Int $\mathbf{J}$ Food Microbiol. 138(3) (2010) 282-286.

[5] Llorente $\mathrm{P}$, Barnech L, Irino $\mathrm{K}$, Rumi M, Bentancor A. Characterization of Shiga toxin-producing Escherichia coli isolated from ground beef collected in different socioeconomic strata markets in Buenos Aires, Argentina. Biomed Res Int. 795104. (2014) doi: 10.1155/2014/795104.

[6] Amézquita-Montes Z, Tamborski M, Kopsombut U, Zhang C, Arzuza O, Gómez-Duarte O. Genetic Relatedness Among Escherichia coli Pathotypes Isolated from Food Products for Human Consumption in Cartagena, Colombia. Foodborne Pathogens and Disease. 12(5) (2015) 454-461.

[7] Toro M, Rivera D, Jiménez M, Díaz L, Navarrete P, Reyes-Jara A. Isolation and characterization of non-O157 Shiga toxinproducing Escherichia coli (STEC) isolated from retail ground beef in Santiago, Chile. Food Microbiol.75 (2018) 55-60. doi: 10.1016/j.fm.2017.10.015.

[8] McGannon CM, Fuller CA, Weiss AA. Different classes of antibiotics differentially influence shiga toxin production. Antimicrob Agents Chemother. 54(9) (2010) 37903798. doi:10.1128/AAC.01783-09

[9] Hatab S, Athanasio R, Holley R, Rodas-Gonzalez A, NarvaezBravo C. Survival and Reduction of Shiga Toxin-Producing Escherichia coli in a Fresh Cold-Pressed Juice Treated with Antimicrobial Plant Extracts. J Food Sci. 81(8) (2016) M198795. doi: 10.1111/1750-3841.13382.

[10] Hussien H, Elbehiry A, Saad M, et al. Molecular characterization of Escherichia coli isolated from cheese and biocontrol of Shiga toxigenic E. coli with essential oils. Ital J Food Saf. 8(3) (2019) 8291. doi:10.4081/ijfs.2019.8291

[11] Patel J, Keelara S, Green J. Inactivation of Escherichia coli O157:H7 and Salmonella on Fresh Herbs by Plant Essential

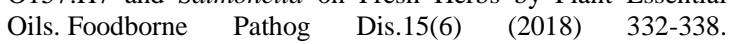
doi:10.1089/fpd.2017.2377

[12] Herrera F, Santos J, Villamizar R. Primer reporte de Escherichia coli Productora de Toxina Shiga no O157 que codifica el gen de la enterohemolisina en carne cruda en Colombia. Archivos Latinoamericanos de Nutrición. 69 (1) (2019) 59-67.

Cruz A, Rodríguez N, Rodríguez C. In vitro evaluation of the antibacterial effect of Bidens pilosa, Lantana camara, Schinus molle and Silybum marianum. Revista U.D.C.A Act. \& Div. Cient. 13 (2) (2010) 117-124.

[14] Ponce, A. G., R. Fritz, C. Del Valle, and S. I. Roura. "Antimicrobial Activity of Essential Oils on the Native Microflora of Organic Swiss Chard." LWT - Food Science and Technology 36(7) (2003) 679-84.
[15]

Weseler A, Geiss HK, Saller R, Reichling J. A novel colorimetric broth microdilution method to determine the minimum inhibitory concentration (MIC) of antibiotics and essential oils against Helicobacter pylori. Pharmazie. 60(7) (2005) 498-502.

Horna G., Astocondor L., Jacobs J., García C. Evaluación de métodos fenotípicos para la detección de Staphylococcus aureus resistente a la meticilina. Revista Española de Quimioterapia. 28(2) (2015) 98-100.

Selim S. Antimicrobial activity of essential oils against vancomycin-resistant enterococci (vre) and Escherichia coli 0157:H7 in feta soft cheese and minced beef meat. Braz J Microbiol. 42(1) (2011) 187-196. doi:10.1590/S151783822011000100023

Djenane D, Aïder M, Yangüela J, Idir L, Gómez D, Roncalés P. Antioxidant and antibacterial effects of Lavandula and Mentha essential oils in minced beef inoculated with E. coli $\mathrm{O} 157: \mathrm{H} 7$ and $S$. aureus during storage at abuse refrigeration temperature. Meat Science 92 (2012) 667-674.

[19] Stashenko E, Martínez J, Ruíz C, Arias G, Durán C, Salgar W, Cala M. Lippia origanoides chemotype differentiation based on essential oil GC-MS and principal component analysis. J Sep Sci. 33(1) (2010) 93-103. doi: 10.1002/jssc.200900452.

Olivero-Verbel J, González-Cervera T, Güette-Fernandez J, Jaramillo-Colorado B, Stashenko E. Chemical composition and antioxidant activity of essential oils isolated from Colombian plants. Revista Brasileira de Farmacognosia, 20(4) (2010) 568574.

[21] Marchese A, Arciola C, Barbieri R, et al. Update on Monoterpenes as Antimicrobial Agents: A Particular Focus on $\mathrm{p}$ -

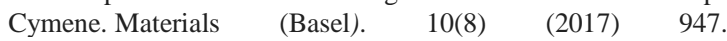
doi:10.3390/ma10080947

Swamy M, Akhtar M, Sinniah U. Antimicrobial Properties of Plant Essential Oils against Human Pathogens and Their Mode of Action: An Updated Review. Evid Based Complement Alternat Med. 2016 (2016):3012462. doi:10.1155/2016/3012462

Djenane D, Yangüela J, Amrouche T, Boubrit S, Boussad N, Roncalés P. Chemical composition and antimicrobial effects of essential oils of Eucalyptus globulus, Myrtus communis and Satureja hortensis against Escherichia coli O157:H7 and Staphylococcus aureus in minced beef. Food Sci Technol Int. 17(6) (2011) 505-515. doi:10.1177/1082013211398803

Yáñez X, Cuadro O. Composición química y actividad antibacteriana del aceite esencial de las especies Eucalyptus globulus y E. camaldulensis de tres zonas de Pamplona (Colombia) Revista Bistua 10(1) (2012) 52-61. 
[27] Callaway T, Carroll J, Arthington J, et al. Citrus products decrease growth of E. coli O157:H7 and Salmonella typhimurium in pure culture and in fermentation with mixed ruminal microorganisms in vitro. Foodborne Pathog Dis. 5(5) (2008) 621627. doi:10.1089/fpd.2008.0088

[28] Sanz-Puig M, Pina-Pérez M, Martínez-Lopez A, Rodrigo D. Escherichia coli $\mathrm{O} 157: \mathrm{H} 7$ and Salmonella Typhimurium inactivation by the effect of mandarin, lemon, and orange byproducts in reference medium and in oat-fruit juice mixed beverage. Food Science and Technology 66 (2016) 7-14.

[29] Pendleton S, Crandall P, Ricke S, Goodridge L, O'Bryan C. Inhibition of beef isolates of E coli $\mathrm{O} 157: \mathrm{H} 7$ by orange oil at various temperatures. J Food Sci. 77(6) (2012) M308-M311. doi:10.1111/j.1750-3841.2012.02689.x

[30] Mahmoudzadeh M, Hosseini H, NasrollahzadeH J, Khaneghah A, Rismanchi M, Chavea R, Shahraz F, Azizkhani M, Mahmoudzadeh L, Haslberger A. Antibacterial Activity of Carum copticum Essential Oil Against Escherichia coli O157:H7 in Meat: Stx Genes Expression. Curr Microbiol 73 (2016) 265272.

[31] Pittman C, Pendleton S, Bisha B, O’Bryan C, Belk K, Goodridge L, Crandall P and Ricke S. Activity of Citrus Essential Oils against Escherichia coli $\mathrm{O} 157: \mathrm{H} 7$ and Salmonella spp. and Effects on Beef Subprimal Cuts under Refrigeration. Journal of Food Science 76 (6), (2011).

[32] Burt S. Essential oils: their antibacterial properties and potential applications in foods--a review. Int J Food Microbiol. 94 (3) (2004) 223-253. doi:10.1016/j.ijfoodmicro.2004.03.022 